\title{
Advanced Surface Modification Resist Process for ArF Lithography
}

\author{
Takahiro Matsuo, Masayuki Endo, Shigeyasu Mori, Koichi Kuhara, Masaru Sasago, \\ Masamitsu Shirai* and Masahiro Tsunooka* \\ Association of Super-Advanced Electronics Technologies (ASET) \\ 292, Yoshida-cho, Totsuka-ku, Yokohama, Kanagawa 244-0817, Japan \\ *College of Engineering, Osaka Prefecture University, Sakai, Osaka 599-8531, Japan
}

\begin{abstract}
Surface modfication resist process (SMR), which gives negative-tone image owing to the polysiloxane formation on exposed resist surface using chemical vapor deposition (CVD), was studied for ArF excimer laser lithography. The selective polysiloxane formation is based on the hydrolysis of alkoxysilane and subsequent condensation in the presence of a photo-induced acid catalyst and sorbed water. We have developed the photoacid generating polymer with a polarity change unit for $0.13 \mu \mathrm{m}$ pattern fabrication. We solved a pattern degradation problem in the dy development by introducing the thernally stable alicyclic unit to this polymer system, and achieved $0.13 \mu \mathrm{m}$ patterns with steep wall profile. Furthermore, we investigated the effect of the water vapor treatment, by which the water was sorbed in the exposed region before CVD. The resolution was improved by adjusting the water vapor treatment time. In the case of too long treatment time, the resolution was degraded by the diffusion of the sorbed water into the unexposed region.

Keywords: polysiloxane, polarity change, surface modification, ArF lithography
\end{abstract}

\section{Introduction}

Top-surface imaging (TSI) process is desirable for expanding the practical resolution below $0.13 \mu \mathrm{m}$ in ArF excimer laser lithography. A lot of challenges of TSI have been reported for the breakthrough of the resolution limit $[1,2]$.

We have developed the surface modification resist process (SMR), in which the exposed polymer surface is modified by the chemical vapor deposition (CVD) of polysiloxane, for ArF lithography [3-6].

The process sequence of SMR is illustrated schematically in Figure 1 . When the resist having photoacid generating units is exposed, the exposed region of the resist becomes acidic and consequently hydrophilic. Water is selectively sorbed in the exposed region by a water vapor treatment. After a CVD treatment, by which the vapor of alkoxysilane and water is exposed at the resist surface, polysiloxane is selectively formed in the presence of an acid and sorbed water. Eventually, negative-tone patterns are fabricated by a dry development. The polysiloxane formation is based on the hydrolysis and condensation of the alkoxysilane by acid catalysis $[7,8]$. The selectivity of the water sorption is an important key to attaining the highly selective surface modification.

We reported that the polymer having a photoacid generating unit and a polarity change unit is available for improving the modification contrast $[5,6]$. Figure 2 shows the photochemical reaction of this polymer system. We used the terpolymer of 1,2,3,4-tetrahydro-1 naphthylideneamino p-styrenesulfonate (NISS), 3-oxocyclohexyl methacrylate (OCMA) and methyl methacrylate (MMA). A sulfonic acid is generated after exposure. Then a carboxylic 
acid is produced owing to the cleavage of 3oxocyclohexyl group by the sulfonic acid after the post-exposure baking (PEB). The water sorption ability is enhanced at the exposed region by producing the carboxylic acid.

In this paper, we report the optimized polymer system having a polarity change unit. We also investigated the effect of the water vapor treatment upon the resolution.

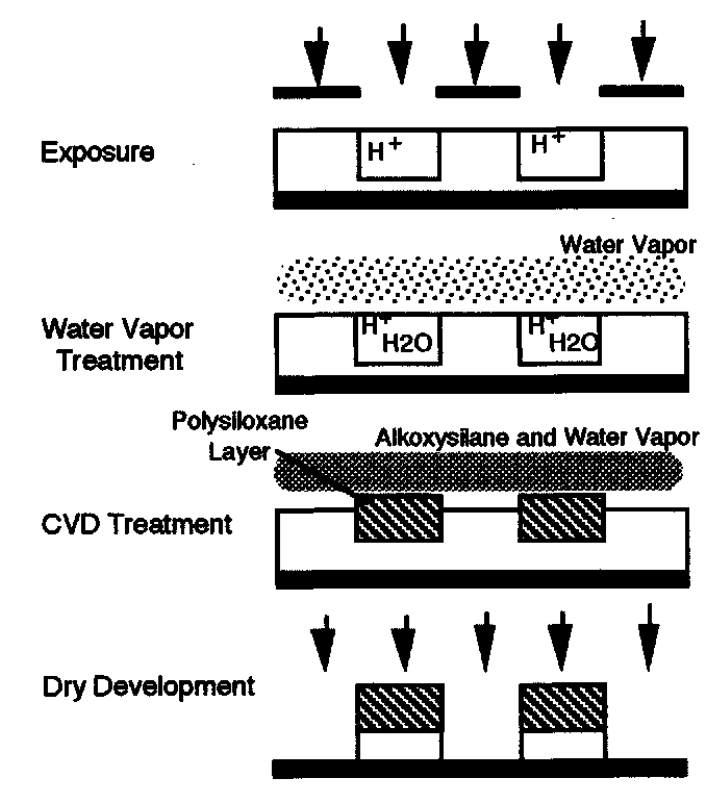

Figure 1. Schematic dagram of surface modification resist process.

\section{Experimental}

\subsection{Polymers}

Figure 3 shows the chemical structures of the terpolymer having the photoacid generating unit, the polarity change unit and the hydrophobic unit. 1,2,3,4-tetrahydro-1naphthylideneamino p-styrenesulfonate (NISS) was used in the photoacid generating unit. 3oxocyclohexyl methacrylate (OCMA) or tetrahydropyranyl methacrylate (THPMA) was used in the polarity change unit. We used methyl methacrylate (MMA) or isobornyl methacrylate (IBMA) in the hydrophobic unit.

\subsection{Process Conditions}

\section{Resist Preparation and Exposure}

Resists were spin-coated on $\mathrm{Si}$ substrate and baked at $90^{\circ} \mathrm{C}$ for $90 \mathrm{sec}$. Exposure was carried out by a prototype ArF excimer laser exposure tool $(\mathrm{NA}=0.55)$. Post-exposure baking (PEB) at $80 \sim 100{ }^{\circ} \mathrm{C}$ for $60 \mathrm{sec}$ was applied to the resist film.

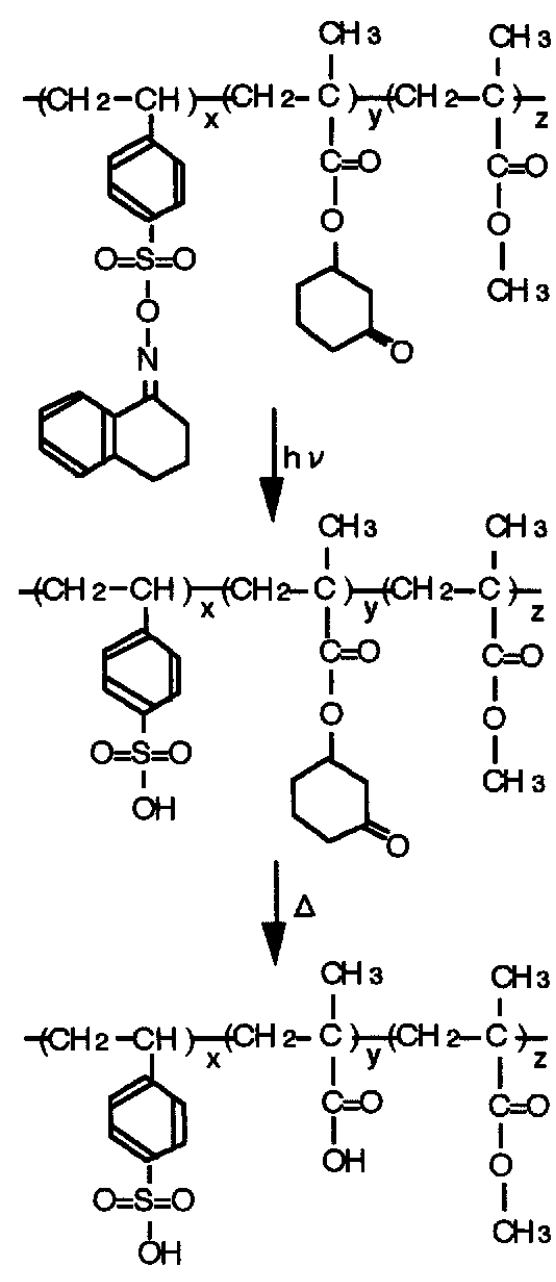

Figure 2. Photochemical reaction of the terpolymer including NISS, OCMA and MMA.

\section{Water Vapor Treatment and CVD Treatment}

A water vapor treatment was performed by carrying the vapor of water into a reaction chamber through a bubbler for $10 \mathrm{~min} . \mathrm{N}_{2}$ was used as a carrier gas. A CVD treatment was sequentially performed by carrying the vapor of methyltrimethoxysilane (MTMOS) and water. The reaction chamber was kept at relative humidity of $75 \%$ and $34^{\circ} \mathrm{C}$.

\section{Dry Development}

The resist was developed by using a Lam TCP9400 after the CVD treatment. The etching conditions were as follows: TCP power of $400 \mathrm{~W}$, bottom power of $100 \mathrm{~W}$, lower electrode temperature at $-10^{\circ} \mathrm{C}, 5 \mathrm{mT}$ orr and oxygen flow of $130 \mathrm{sccm}$. 


\subsection{Measurement}

The amount of formed polysiloxane was evaluated by measuring FTIR absorbance in Si$\mathrm{CH}_{3}\left(1270 \mathrm{~cm}^{-1}\right)$. The cross-sectional pattern profiles were observed by a scanning electron microscope (SEM).

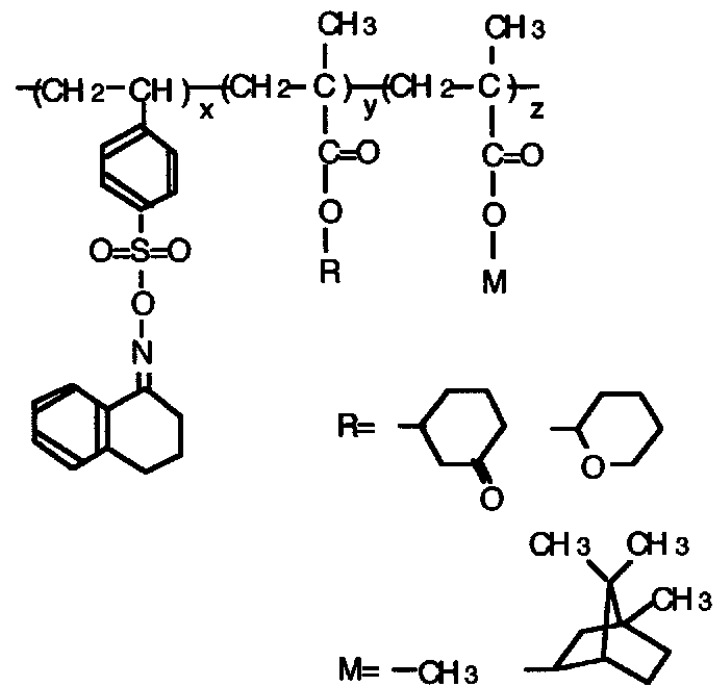

Figure 3. Chemical structures of polymers having polarity change units.

\section{Results and Discussion}

\subsection{Infiuence of Polymer Structure on Resolution}

We examined the pattern formation using the terpolymer $\mathrm{NISS}_{0.14}-\mathrm{THPMA}_{0.32}-\mathrm{MMA}_{0.54}$ and NISS $_{0.14}$ THPMA $_{0.50}-$ MMA $_{0.36}$ (Figure 4). PEB was carried out at $100^{\circ} \mathrm{C}$ for $60 \mathrm{sec}$. The water vapor treatment and the CVD treatment were performed for $10 \mathrm{~min}$ and for $15 \mathrm{~min}$ respectively. $0.14 \mu \mathrm{m}$ line-and-space (L/S) patterns were obtained with steep wall profile at $110 \mathrm{~mJ} / \mathrm{cm}^{2}$ in NISS $_{0.14}-$ THPMA $_{0.32}-$ MMA $_{0.54}$. In the terpolymer NISS $_{0.14}-$ THPMA $_{0.50}-$ MMA $_{0.36}, \quad 0.13 \mu \mathrm{m} \quad$ LS patterns were separated with tapered wall profile at $135 \mathrm{~mJ} / \mathrm{cm}^{2}$. Although the resolution improved with increase of the ratio of THPMA, the pattern profile tended to be degraded. It is considered that the cause of the pattern degradation is that the plasma heats up the resist pattern in the dry development.

In order to improve the thermal stability of the resist, we synthesized the terpolymer with isobornyl methacrylate (IBMA), which has an alicyclic group, instead of MMA. The glass transition temperature ( $\mathrm{Tg}$ ) and decomposition temperature (Td) were measured in the

\begin{tabular}{|c|c|c|}
\hline & NISS $_{0.14}-$ THPMA $_{0.32}-$ MMA $_{0.54}$ & NISS $_{0.14}-$ THPMA $_{0.50}-$ MMA $_{0.36}$ \\
\hline $0.16 \mu \mathrm{m}$ L/S & & \\
\hline $0.15 \mu \mathrm{m}$ L/S & 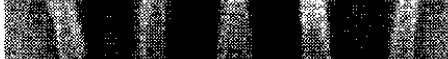 & \\
\hline $0.14 \mu \mathrm{m} \mathrm{LS}$ & 2014 & \\
\hline $0.13 \mu \mathrm{m}$ LS & & \\
\hline
\end{tabular}

Figure 4. SEM photographs of various line-and-space patterns using NISS $\mathrm{No.14}^{-\mathrm{THPMA}_{0.32}-\mathrm{MMA}_{0.54} \text { and NISS}} \mathrm{N}_{0.14^{-}}$ THPMA $_{0.50^{-}}$MMA $_{036}$. Resist thickness: $0.6 \mu \mathrm{m}$. PEB: $100^{\circ} \mathrm{C}$ for $60 \mathrm{sec}$. $\mathrm{H}_{2} \mathrm{O}$ treatment time: $10 \mathrm{~min}$. CVD time: $15 \mathrm{~min}$. 
terpolymer with IBMA and the terpolymer with MMA by using differential scanning calorimetry (DSC). Both a $\mathrm{Tg}$ and a $\mathrm{Td}$ increased by introducing IBMA as shown in Table 1. Figure 5 shows cross-sectional SEM photographs of various $L / S$ patterns using the terpolymer NISS $_{0.18}$ THPMA $_{0.45}-$ IBMA $_{0.37} \cdot 0.13 \mu \mathrm{m}$ patterns were fabricated without the degradation of pattern profile at $195 \mathrm{~mJ} / \mathrm{cm}^{2}$.

Table 1. Thermal properties of the terpolymer having a polarity change unit.

\begin{tabular}{c|cc}
\hline Polymers & $\operatorname{Tg}\left({ }^{\circ} \mathrm{C}\right)$ & $\operatorname{Td}\left({ }^{\circ} \mathrm{C}\right)$ \\
\hline NISS $_{0.09}$ THPMA $_{0.54}$-MMA $_{0.37}$ & 137 & 143 \\
NISS $_{0.09}$ THPMA $_{0.61}$-IBMA $_{0.30}$ & 146 & 159 \\
\hline
\end{tabular}

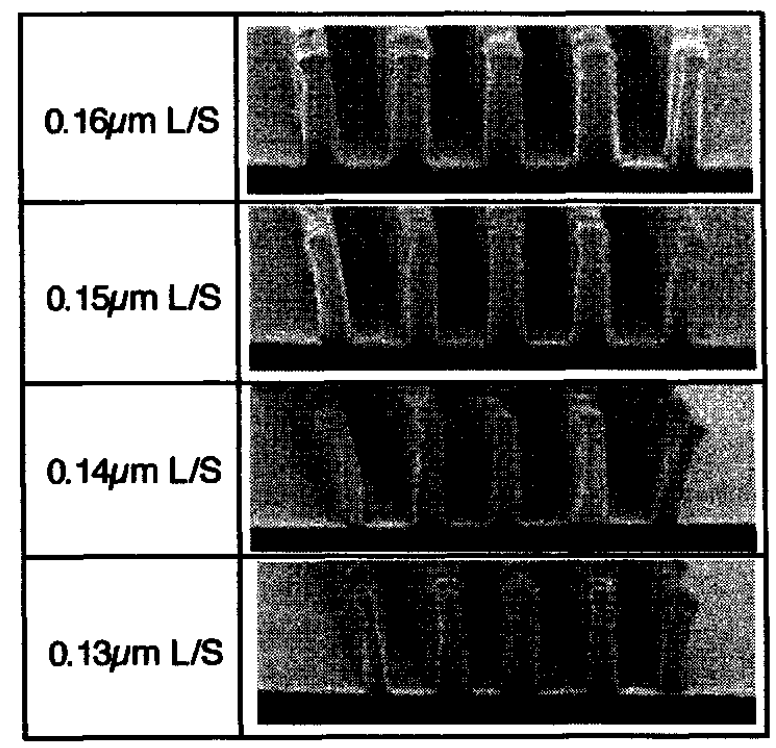

Figure 5. SEM photographs of various LS patterns using the terpolymer NISS $_{0.18}-$ THPMA $_{0.45}-$ IBMA $_{0.37}$. Exposure energy: $195 \mathrm{~mJ} / \mathrm{cm}^{2}$. PEB: $100^{\circ} \mathrm{C}$ for $60 \mathrm{sec}$. $\mathrm{H}_{2} \mathrm{O}$ treatment time: $10 \mathrm{~min}$. CVD time: $30 \mathrm{~min}$.

\subsection{Influence of Water Vapor Treatment Time on Resolution}

The water sorption by a water vapor treatment plays an important role for the hydrolysis reaction of the diffused alkoxysilane in the resist film.

We examined the relationship between the water vapor treatment time and the amount of formed polysiloxane in the exposed region (Figure 6). NISS $_{0.13}-\mathrm{OCMA}_{0.13}-\mathrm{MMA}_{0.74}$ was used in resist. $\mathrm{PEB}$ was performed at $80^{\circ} \mathrm{C}$ for $60 \mathrm{sec}$, and CVD treatment was carried out for 30min. When CVD treatment was carried out without the water vapor treatment, a very small amount of polysiloxane was formed. The sufficient amount of polysiloxane was obtained by the water vapor treatment for $10 \mathrm{~min}$. It is considered that the polysiloxane formation was promoted, because the amount of the sorbed water increased by the water vapor treatment.

On the other hand, the formed polysiloxane decreased, when the treatment time was more than $20 \mathrm{~min}$. It is considered that the excessive water sorption weakened the acid catalytic ability, and reduced the polysiloxane [9].

Figure 7 shows the SEM photographs of the cross-sectional shape of the polysiloxane layer in the various water vapor treatment times. The cross-section of the resist film was treated by oxygen plasma before observing SEM. NISS $_{0.15}-$ OCMA $_{0.30}-$ MMA $_{0.55}$ was used in resist. Although the polysiloxane layer was not observed below $0.2 \mu \mathrm{m}$ features in the case of $7 \mathrm{~min}, 0.15 \mu \mathrm{m}$ features was clearly separated for

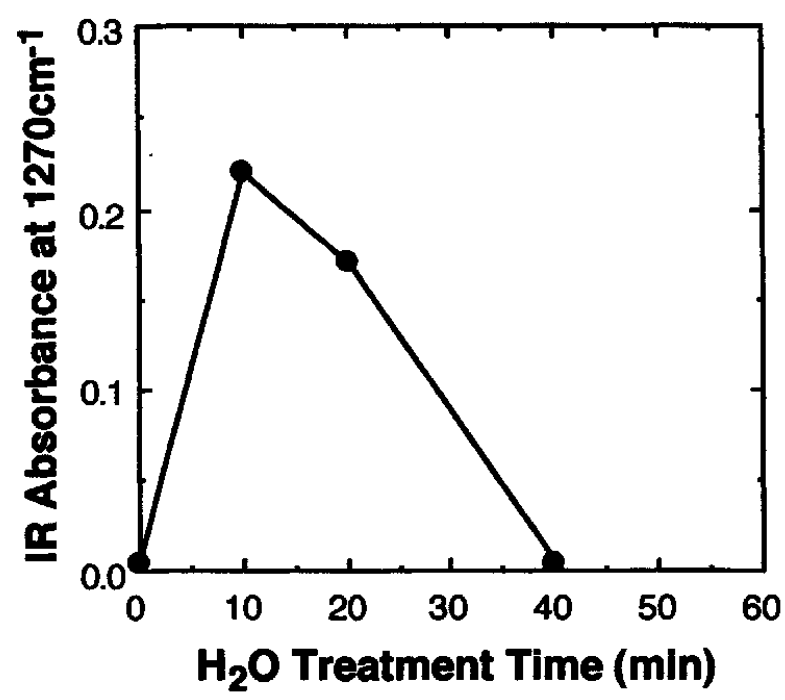

Figure 6. Relationship between the water vapor treatment time and the amount of polysiloxane in the exposed region using NISS $_{0.13}-\mathrm{OCMA}_{0.13}-\mathrm{MMA}_{0.74}$. 
$10 \mathrm{~min}$ owing to the sufficient water sorption in the exposed region. However, the modification contrast of the polysiloxane was reduced in the case of longer treatment for $15 \mathrm{~min}$. It is due to the diffusion of sorbed water from the exposed region into the unexposed region.

Moreover, we studied the influence of the water vapor treatment time on the resolution in the terpolymer NISS $_{0.18}$-THPMA $_{0.45}-$ IBMA $_{0.37}$. The pattern was not fabricated in the case of the treatment for $5 \mathrm{~min}$. As shown in Figure 5, $0.13 \mu \mathrm{m}$ patterns was obtained by the treatment for $10 \mathrm{~min}$. In the longer treatment for $15 \mathrm{~min}$, the resolution was limited up to $0.16 \mu \mathrm{m}$ because of the low modification contrast, as shown in Figure 8.

Therefore, the diffusion of sorbed water into the unexposed region must be suppressed in the water vapor treatment for achieving high resolution.

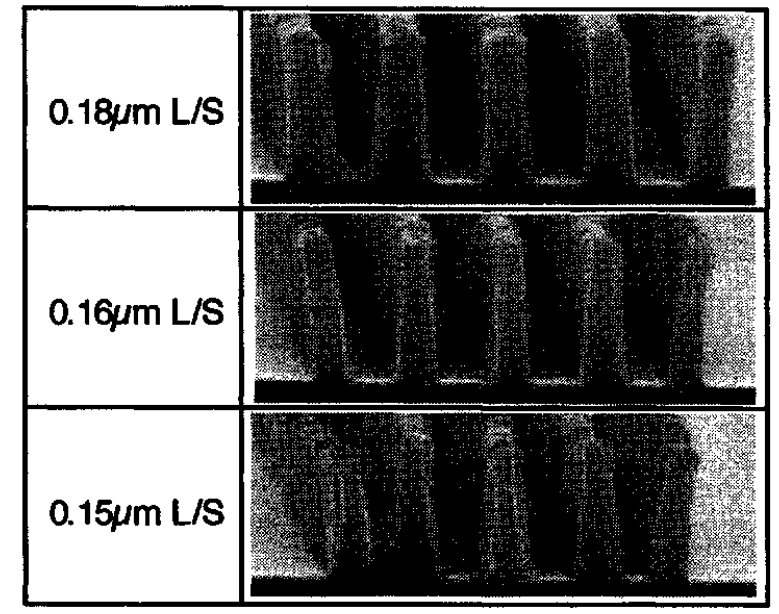

Figure 8. SEM photographs of various L/S pattems using the terpolymer NISS $_{0.18}$ THPMA $_{0.45}-$ IBMA $_{0.37}$. Exposure energy: $195 \mathrm{~mJ} / \mathrm{cm}^{2}$. PEB: $100^{\circ} \mathrm{C}$ for 60sec. $\mathrm{H}_{2} \mathrm{O}$ treatment time: $15 \mathrm{~min}$. CVD time: $30 \mathrm{~min}$.

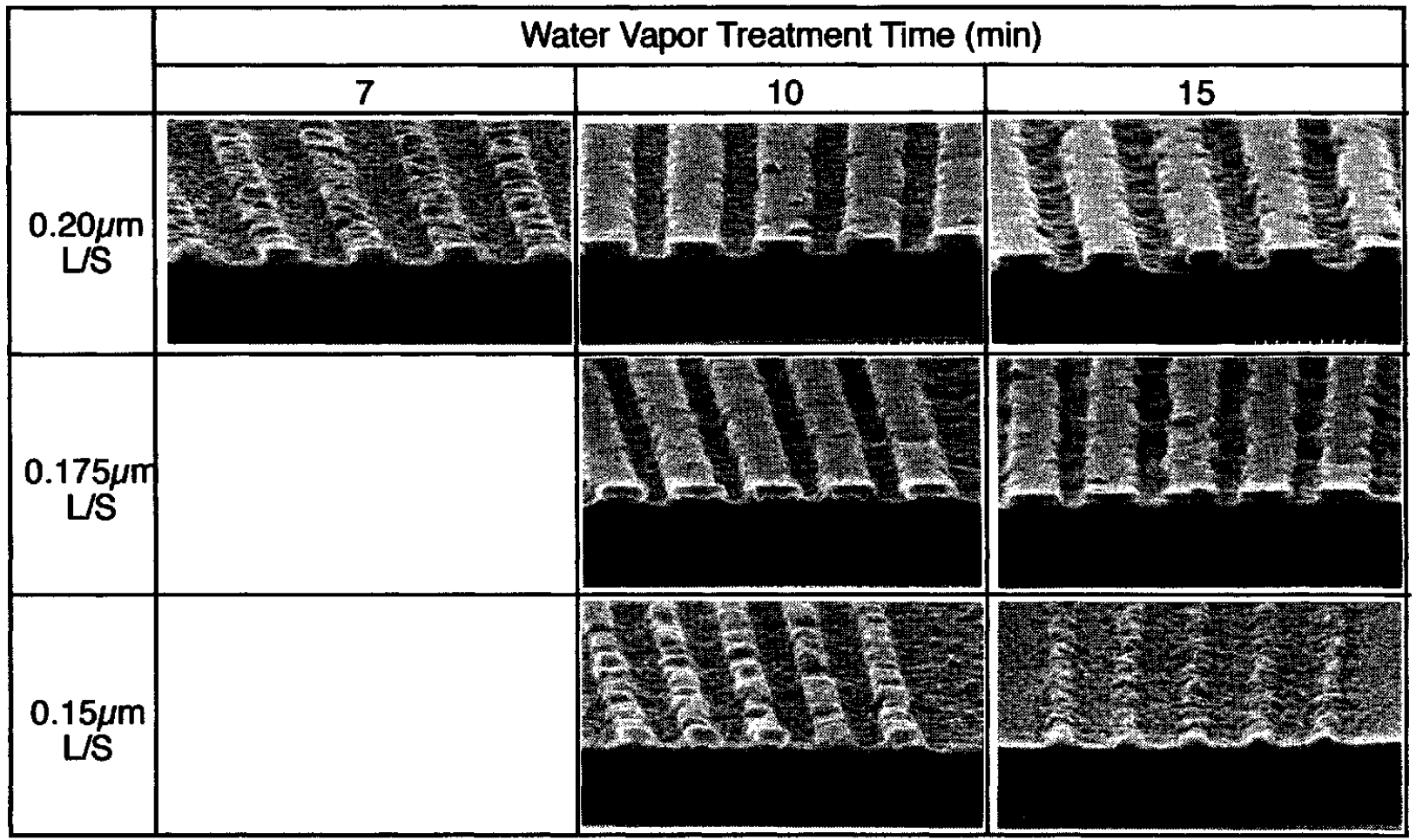

Figure 7. SEM photographs of the cross-sectional shape of the polysiloxane layer in various water vapor treatment time. NISS ${ }_{0.15}-\mathrm{OCMA}_{0.30}-\mathrm{MMA}_{0.55}$ was used in resist. Exposure energy was $40 \mathrm{~mJ} / \mathrm{cm}^{2}$. PEB was carried out at $80^{\circ} \mathrm{C}$ for $60 \mathrm{sec}$. CVD was performed for $30 \mathrm{~min}$. 


\section{Conclusion}

We have developed the polymer system having a polarity change unit for $\mathrm{ArF}$ lithography using SMR. We clarified that the pattern degradation by heating must be prevented in the dry development. We have solved the problem by introducing the thermally stable alicyclic unit to the polymer, and achieved $0.13 \mu \mathrm{m}$ patterns with steep wall profile.

Furthermore, we have studied the effect of the water vapor treatment upon the resolution. The resolution was improved by adjusting the water vapor treatment time. Although the water sorption by the treatment is essential to a sufficient polysiloxane formation in the exposed region, the excessive treatment reduces the resolution owing to the diffusion of the sorbed water into the unexposed region.

\section{References}

1) K. Maeda, T. Ohfuji, N. Aizaki and E. Hasegawa, Proc. SPIE, 2438, (1995) 465.
2) S. Mori, K. Kuhara, T. Ohfuji and M. Sasago, Proc. SPIE, 3049, (1997) 146.

3) M. Shirai, M. Hayashi and M. Tsunooka, Macromolecules, 25, (1992) 195.

4) T. Matsuo, M. Endo, M. Shirai and $M$. Tsunooka, J. Vac. Sci. Technol., B14(6), (1996) 4212.

5) T. Matsuo, M. Endo, $M$. Shirai and $M$. Tsunooka, J. Photopolym. Sci. Technol., 10, (1997) 595.

6) T. Matsuo, M. Endo, S. Mori, K. Kuhara, M. Sasago, M. Shirai and M. Tsunooka, Proc. SPIE, 3333, (1998) in press.

7) J. Sanchez and A. McCormick, "Chemical Processing of Advanced Materials", L. L. Hench and J. K. West, Ed., John Wiley and Sons, New York (1992) p. 43.

8) A. McCormick, "Sol-Gel Processing and Applications", Y. A. Attia, Ed., Plenum Press, New York (1994) p. 3.

9) T. Matsuo, M. Endo, M. Shirai and $M$. Tsunooka, J. Electrochem. Soc., 144 (1997) 2903. 